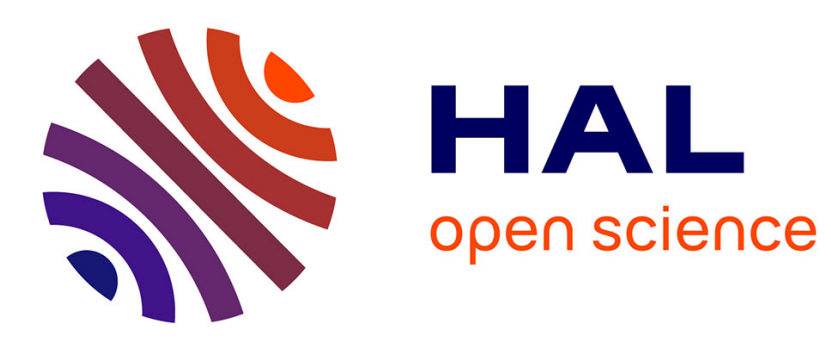

\title{
When avoiding failure improves performance: Stereotype threat and the impact of performance goals
}

Aïna Chalabaev, Brenda Major, Philippe Sarrazin, François Cury

\section{To cite this version:}

Aïna Chalabaev, Brenda Major, Philippe Sarrazin, François Cury. When avoiding failure improves performance: Stereotype threat and the impact of performance goals. Motivation and Emotion, 2012, 36 (2), pp.130-142. 10.1007/s11031-011-9241-x . halshs-01074606

\section{HAL Id: halshs-01074606 \\ https://shs.hal.science/halshs-01074606}

Submitted on 14 Oct 2014

HAL is a multi-disciplinary open access archive for the deposit and dissemination of scientific research documents, whether they are published or not. The documents may come from teaching and research institutions in France or abroad, or from public or private research centers.
L'archive ouverte pluridisciplinaire HAL, est destinée au dépôt et à la diffusion de documents scientifiques de niveau recherche, publiés ou non, émanant des établissements d'enseignement et de recherche français ou étrangers, des laboratoires publics ou privés. 


\begin{abstract}
When Avoiding Failure Improves Performance: Stereotype Threat and the Impact of Performance Goals
\end{abstract}

\author{
Aïna Chalabaev \\ University of California, Santa Barbara, and University of Grenoble, France \\ Brenda Major \\ University of California, Santa Barbara \\ Philippe Sarrazin \\ University of Grenoble, France \\ François Cury \\ CNRS Provence University and Toulon Var South University, France
}

\title{
Accepted Manuscript
}

Motivation and Emotion (2012), 36, 130-142

\begin{abstract}
Author's Note: Aïna Chalabaev is now at University of Nice-Sophia Antipolis, France ${ }^{1}$. Correspondance concerning this article should be addressed to Aïna Chalabaev, UFR STAPS, 261 route de Grenoble, 06205 Nice cedex 3, France. e-mail: aina.chalabaev@unice.fr; phone: +33 (0)4 922965 24; fax: +33 (0)4 92296549.
\end{abstract}




\begin{abstract}
We examined the impact of inducing performance-avoidance and approach goals (versus no goal) on women's math performance in stereotype threatening versus nonthreatening situations. Two experiments showed that inducing either stereotype threat (versus nothreat) or a performance-avoidance goal (versus no goal) alone led to decreased math performance. However, inducing both stereotype threat and a performance-avoidance goal increased women's performance and challenge appraisals. These findings are consistent with the theory of regulatory fit. Performance and challenge appraisals increased when there was a fit between the motivation associated with stereotype threat (avoid failure) and the induced goal (avoid performing worse than others). Implications for stereotype threat, achievement goals and regulatory focus theories are discussed. Keywords: stereotype threat, achievement goals, regulatory fit, avoidance, approach.
\end{abstract}


When Avoiding Failure Improves Performance: Stereotype Threat and the Impact of Performance Goals

Understanding social determinants of academic achievement has been the focus of numerous theories, including stereotype threat (ST) theory (Steele, 1997). ST is a situationally-induced identity threat "that can arise when one knows that he or she can possibly be judged or treated negatively on the basis of a negative stereotype about one's group" (Goff, Steele, \& Davies, 2008, p. 92). In this situation, individuals may feel extra pressure not to fail so as not to confirm the stereotype. In turn, this threat has been shown to hamper academic performance through motivational (e.g., motivation to avoid failure), affective (e.g., increased anxiety), cognitive (e.g., reductions in working memory capacity), and physiological (e.g., stress) processes (see Schmader, Johns, \& Forbes, 2008, for a review).

Although most prior research has examined the types of groups and domains susceptible to ST effects, a growing body of research focuses on how ST can be eliminated. These studies have shown that ST effects may be "turned off" under several conditions: when stereotypes are retrained (Forbes \& Schmader, 2010), when tests are framed as a challenge (Alter, Aronson, Darley, Rodriguez, \& Ruble, 2010), when stereotyped individuals adopt a malleable theory of intelligence (Aronson, Fried, \& Good, 2002), affirm a valued attribute (Martens, Johns, Greenberg, \& Schimel, 2006), or are presented with positive role models (e.g., Marx, Ko, \& Friedman, 2009; Marx, Stapel, \& Muller, 2005; McIntyre, Paulson, \& Lord, 2002).

The present study examines a motivational approach to eliminating ST. Drawing on the concept of regulatory fit (Higgins, 2000), we hypothesize that inducing a 
performance-avoidance goal context may ironically reduce the negative effects of ST on women's performance in mathematics. Math is a domain susceptible to ST effects in women (e.g., Inzlicht \& Ben Zeev, 2000; Schmader, 2002; Spencer, Steele, \& Quinn, 1999). Following, we provide a framework for our hypothesis based on ST, achievement goals (e.g., Elliot \& Church, 1997), and regulatory focus (Higgins, 1997; 1998) theories.

\section{Stereotype Threat, Performance-avoidance Goals, and Regulatory Fit}

Achievement goals theory addresses how motivation affects individuals' behavior in achievement situations (e.g., Elliot, 2005; Elliot \& Church, 1997; Harackiewicz, Barron, Pintrich, Elliot, \& Thrash, 2002; Murayama \& Elliot, 2009). The trichotomous achievement goals theory (Elliot \& Church, 1997) distinguishes mastery goals, focused on self-referenced and task-based standards of competence, from performance-approach and performance-avoidance goals, focused on demonstrating competence relative to others. Whereas performance-avoidance goals focus on avoiding incompetence relative to others, performance-approach goals focus on demonstrating competence relative to others $^{2}$. Many studies suggest that compared to performance-approach goals, performance-avoidance goals typically are associated with more maladaptive achievement outcomes, including increased anxiety, loss of motivation, and poorer performance (e.g., Cury, Elliot, Sarrazin, Da Fonseca, \& Rufo, 2002; Elliot \& Harackiewicz, 1996; Elliot \& McGregor, 1999; Elliot, McGregor, \& Gable 1999; Elliot, Shell, Bouas, \& Maier, 2005; Urdan, 2004; Van Yperen, 2003; for a review see Elliot, 2005).

Here, we test the counterintuitive hypothesis that experimentally inducing a performance-avoidance goals context will improve the performance of women under ST. 
Although this hypothesis appears to contradict past studies showing that such goals have negative effects on achievement-related outcomes, prior research on regulatory focus theory (Higgins, 1997, 1998) suggests that performance-avoidance goals may not be systematically maladaptive. According to this model, people may pursue two kinds of regulatory goals: promotion and prevention. When they are promotion-oriented, people pursue desirable outcomes (e.g., gains, successes); when they are prevention-oriented, they strive to avoid undesirable outcomes (e.g., losses, failures). Prevention goals share conceptual similarities with performance-avoidance goals: in the former, success is experienced when negative outcomes are absent; in the latter, success is achieved when performing poorly relative to others is avoided.

As in the achievement goals literature, early work on regulatory focus considered that prevention concerns were associated with detrimental outcomes, such as lower persistence on difficult tasks or after experiencing failure (e.g., Crowe \& Higgins, 1997), and lower creative thought (e.g., Friedman \& Förster, 2001). Later studies, however, revealed that prevention goals do not necessarily lead to negative outcomes. Indeed, when people are encouraged to pursue strategies that match their regulatory goal, they show enhanced motivation and performance (e.g., Freitas \& Higgins, 2002; Keller \& Bless, 2006; Lockwood, Jordan, \& Kunda, 2002), and report feeling better (e.g., Camacho, Higgins, \& Luger, 2003; Higgins, 2000). This phenomenon is called regulatory fit. For example, Keller and Bless (2006) showed that experimentally encouraging motivation to avoid failure enhanced academic performance of individuals that were chronically prevention-oriented. This performance boost occurred because such individuals focus on information relevant to the avoidance of failure and on 
strategies geared toward preventing negative outcomes (Higgins, Roney, Crowe, \& Hymes, 1994). Thus, tasks that are framed in terms of prevention match the sensitivity to losses of prevention-oriented individuals, increasing in turn their motivation and persistence on the task (Shah, Higgins, \& Friedman, 1998).

Based on these results, and despite existing research consistently associating performance-avoidance goals with negative outcomes, we assumed that regulatory fit may also occur when these goals are experimentally induced under ST. Indeed, past studies have shown that individuals under ST adopt a motivation to avoid failure, conceptualized in terms of performance-avoidance goals (e.g., Brodish \& Devine, 2009; Chalabaev, Sarrazin, Stone, \& Cury, 2008; Smith, Sansone, \& White, 2007) or prevention goals (e.g., Seibt \& Förster, 2004). Therefore, experimentally inducing an avoidance setting should "fit" with the avoidance motivation triggered by the ST situation, thereby enhancing performance. Grimm, Markman, Maddox, and Baldwin (2009) provided some initial evidence in support of this assumption. They manipulated the reward structure of a math task such that in one condition, the gains reward structure (promotion induction), participants gained more points for correct answers than for incorrect answers; in a second condition, the loss reward structure (prevention induction), they lost fewer points for correct answers than for incorrect answers. When ST was paired with the loss reward structure, and hence an induced avoidance strategy, females' performance on the test was boosted compared to when it was paired with a promotion context, a phenomenon they called stereotype fit. Given that both prevention and performance-avoidance goals involve a focus on avoidance, these results provide support 
for our hypothesis that inducing a performance-avoidance goals context may act as a buffer against $\mathrm{ST}$.

\section{Stereotype Threat and Performance-approach Goals}

Our discussion has emphasized the implications of theory and research on performance-avoidance goals for understanding the performance of members of negatively stereotyped groups under conditions of ST. Although not the primary focus of our research, we also examined the potential performance implications of inducing a performance-approach goals context among individuals under ST. Drawing on regulatory focus theory, we hypothesized that inducing both ST and performanceapproach goals could lead to a regulatory mismatch, because people who are experiencing ST adopt a prevention concern, which does not "fit" with the performanceapproach goal. If so, we would expect the induction of a performance-approach goal combined with ST to undermine performance.

\section{Current Research}

Two studies investigated the impact of manipulated performance goals contexts on women's math performance in situations that did or did not activate the well-known stereotype that females have poor mathematical ability. Both experiments employed a 2 (ST or no threat) $\times 3$ (performance-avoidance goal or performance-approach goal or no goal) between-subject factorial design.

The primary aim was to test the hypothesis that experimentally inducing performance-avoidance goals in people under ST leads to regulatory fit, thus reducing the negative effects of ST on women's math performance. To our knowledge, the research by Grimm et al. (2009) provides the only evidence in support of this counterintuitive 
hypothesis, and they did not directly manipulate performance avoidance and approach goals. Although performance-based goals and regulatory concerns are both characterized by an avoidance / approach dimension, performance-based goals also comprise a social comparison dimension (i.e., desire to perform well relative to others). Thus, finding evidence in support of our hypothesis would not only further establish the reliability of the stereotype fit hypothesis but would also extend its generalizability to different avoidance-related constructs.

Performance goals were manipulated by telling women that their score would be diagnostic of strong (approach goal) or weak (avoidance goal) ability relative to others. This manipulation has been adapted from past studies examining its effects in the context of math performance (Brown \& Josephs, 1999; Keller \& Bless, 2006). In a ST framework, Brown and Josephs (1999) predicted that ST occurs because individuals are concerned about the possibility of performing poorly. According to these authors, results confirmed their hypotheses by showing that women performed more poorly when the math test was diagnostic of weak ability than when it was diagnostic of strong ability. These findings apparently contradict our regulatory fit hypothesis by indicating that inducing an avoidance context under ST impairs performance. However, a closer examination of their design reveals the absence of a ST condition with no goal induction. Therefore, it is not possible to conclude from these results whether inducing an avoidance context alleviated ST effects or not. Our design included this control condition in order to examine this question.

In a regulatory focus framework, Keller and Bless (2006) used the same goal manipulation to induce promotion and prevention concerns. They tested whether these 
manipulated concerns could lead to regulatory fit, depending on individuals' chronic selfregulatory focus. Importantly, the gender fairness of the test was emphasized in order to limit the potential occurrence of ST, which was therefore not examined in this study. In sum, although past research has examined effects of our manipulation of performance goals in a math context, the current differs in design and theoretical approaches.

\section{Study 1}

\section{Method}

Participants. Eighty-six Caucasian female undergraduates at the University of California, Santa Barbara (UCSB), took part in this study for introductory psychology course credit or for $\$ 10$. They were randomly assigned to one of six conditions in a 2 (Test description: math ability or problem-solving ability) $\times 3$ (Goal Type: performanceavoidance goal or performance-approach goal or no goal) between subject factorial design.

Procedure. During a prescreening survey administered at the start of the quarter, all participants reported their score on the quantitative section of the SAT. This variable was used as a control in tests of the effects of our manipulations on performance. Participants were scheduled for the experiment individually. Upon arriving at the laboratory, they were greeted by a female experimenter (blind to condition), who seated them in front of a computer in a cubicle. After having read an information sheet and giving consent, participants listened to a tape recording of the task description, which differed according to what condition they had been randomly assigned.

Stereotype threat manipulation. Tape-recorded instructions were used to manipulate ST. This manipulation was based on those used in previous research (e.g., 
Johns, Schmader, \& Martens, 2005), and involved telling women that they would take a test that measured either math skills (ST) or problem-solving skills (no threat). The experimenter was unaware of which instructions the participants heard.

Achievement goal manipulation. Participants next heard tape-recorded instructions designed to manipulate performance goals contexts. Similar to past goal manipulations (e.g., Chalabaev et al., 2009, Cury et al., 2002), these instructions referred to competence relative to others, by informing participants that their performance on the math (problem-solving) test would be compared to the performance of other university students.

Also, based on Brown and Josephs (1999) manipulation, participants received instructions that varied depending on the Goal Type condition to which they had been assigned. Specifically, participants in the performance-avoidance goal condition heard that a scoring method would be used to identify students who had weak math or problemsolving ability (not students who had medium or strong ability). In contrast, participants in the performance-approach goal condition heard that a scoring method would be used to identify students who had strong math or problem-solving ability (not students who had weak or medium ability) (see also Chalabaev et al., 2009 for a similar manipulation).

In the no goal condition, no information about interpersonal comparisons and the scoring method was mentioned. After the instructions, participants completed manipulation check items.

Manipulation checks. As a check on the experimental manipulations, participants were next asked to indicate on an overt item what type of ability the test was measuring. In addition, they were asked the extent to which they agreed with two 
statements (adapted from Cury et al., 2002): “The purpose of this task is to select the students who are exceptionally weak" and "The purpose of this task is to select the students who are exceptionally strong". Participants indicated their agreement on scales from 1 (strongly disagree) to 7 (strongly agree).

Task. Next, participants were informed that the task would begin and were asked to read instructions that appeared on the computer monitor. After the above-mentioned instructions were re-stated, participants learned that the task was composed of 10 multiple-choice word problems with 5 answer choices, and were informed that each problem would stay on the screen for one minute. After one minute had passed the computer would automatically advance to a blank screen lasting four seconds and then to the next problem. They were asked to respond while the problem was on the screen or during the following four seconds so that the experimenter could record them in the control room. The task consisted of ten math word problems taken from a GRE practice book (e.g., "Bob and Alice can finish a job together in 3 hours. If Bob can do the job by himself in 5 hours, what percent of the job does Alice do? Answer 1: 20\%, Answer 2: 30\%, Answer 3: 40\%, Answer 4: 50\%, Answer 5: 60\%”).

Following the completion of the task, participants were thanked and fully debriefed.

\section{Results and Discussion}

Manipulation checks. We performed 2 (ST: Threat vs No threat) $\times 3$ (Goal Type: Performance-avoidance, Performance-approach, or No goal) analyses of variance (ANOVA) on each manipulation check item. The ST manipulation was perceived as intended: participants in the math ability condition perceived the task as more diagnostic 
of math ability than did participants in the problem-solving ability condition, $F(1,80)=$ $391.66, p<.001, \eta^{2}=.83$. No other main or interactive effect reached significance $(F<$ 1). The Goal Type manipulation also was perceived as intended. On the "strong students" item, only the main effect of goal type was significant, $F(2,80)=165.20, p<$ $.001, \eta^{2}=.81$, and post hoc analyses showed all three conditions differed significantly from one another. Participants in the Performance-approach goal conditions agreed significantly more with this item $(M=6.10)$ than did participants in the Performanceavoidance goal $(M=1.23), F(1,80)=306.54, p<.001, \eta^{2}=.79$ or No goal $(M=2.41)$ conditions, $F(1,80)=166.24, p<.001, \eta^{2}=.68$. In addition, participants in the No goal conditions agreed significantly more with this item than participants in the Performanceavoidance goal conditions, $F(1,80)=17.10, p<.001, \eta^{2}=.18$. No other main or interactive effect was significant $\left(F_{\mathrm{S}}<1.00\right)$.

Concerning the "weak students" item, only a main effect of goal type was observed, $F(2,80)=52.36, p<.001, \eta^{2}=.57$. Participants in the Performance-avoidance goal conditions agreed significantly more with this item $(M=5.73)$ than did participants in the Performance-approach goal $(M=1.81), F(1,80)=88.17, p<.001, \eta^{2}=.52$, or No goal $(M=2.28), F(1,80)=65.30, p<.001, \eta^{2}=.45$, conditions. The Performanceapproach goal conditions did not significantly differ from the No goal conditions, $F(1$, $80)=1.21, p=.27, \eta^{2}=.01$. The main effect of ST $(F<1.00)$ and the interaction effect, $F(1,80)=1.82, p=.17$, were not significant.

Task performance. Our main dependent variable was performance accuracy, which is the number of mathematical questions a participant answered correctly divided by the number of questions that the participant answered. This performance measure has 
been consistently used in the ST literature (e.g., Lawrence, Marks, \& Jackson, 2010; Schmader, 2002; Shih, Pittinsky, \& Ambady, 1999; Steele \& Aronson, 1995). We conducted a $2 \times 3$ analysis of covariance (ANCOVA) on this measure, controlling for SAT quantitative score (see Figure 1). The means and standard deviations of each experimental group are described in Table 1. The main effect of ST was significant, $F$ (1, 79) $=4.75, p=.03, \eta^{2}=.06$, with participants performing better when the task was described as a measure of problem-solving ability (Adj $M=0.64)$ than when it was described as a measure of math ability (Adj $M=0.55)$. The main effect of Goal Type was not significant $(F<1.00)$.

More importantly, the predicted ST $\times$ Goal Type interaction was significant, $F(2$, $79)=4.08, p=.02, \eta^{2}=.09$. We probed this interaction by testing our predictions. First, we tested the simple main effect of ST within the No goal condition to determine whether a "classic" ST effect occurred. As predicted, women told that the test was a measure of math ability performed significantly worse (Adj $M=0.47$ ) than did those told that the same test was a measure of problem-solving ability (Adj $M=0.69), F(1,79)=9.26, p=$ $.003, \eta^{2}=.10$.

We next tested the effect of inducing a performance-avoidance goal (vs. no goal) context on performance. Consistent with predictions and the literature on achievement goals, in the No threat conditions, follow-up simple comparisons showed that participants performed significantly worse in the Performance-avoidance goal condition (Adj $M=$ 0.55 ) compared to no goal condition, $F(1,79)=4.13, p=.04, \eta^{2}=.05$. In contrast, consistent with predictions and the literature on regulatory fit, in the ST conditions, performance in the Performance-avoidance goal condition was marginally higher (Adj $M$ 
$=0.61)$ compared to the No goal condition, $F(1,79)=3.72, p=.06, \eta^{2}=.05$. Moreover, performance under ST/performance-avoidance goal did not differ from performance in the No goal/No threat condition, $F(1,79)=1.28, p=.26, \eta^{2}=.02$.

Third, we examined the effect of performance-approach goal (vs. no goal) on performance. Inducing a performance-approach goal did not lead to higher performance among women in either the No threat $(\operatorname{Adj} M=0.66)(F<1.00)$ or Threat conditions $($ Adj $M=0.56), F(1,79)=1.30, p=.26, \eta^{2}=.02$. Moreover, in the latter conditions, performance did not differ when performance-approach or performance-avoidance goals contexts were induced $(F<1.00)$. Finally, consistent with a regulatory fit perspective, when both ST and a performance-approach goal were induced, women performed more poorly than in the No Threat / No Goal condition, $F(1,79)=4.02, p=.05, \eta^{2}=.05$.

\section{Summary}

Study 1 showed that the impact of inducing a performance-avoidance goal on women's performance on a math test differed depending on whether a test was described as measuring problem-solving ability (a non threatening domain for women) versus math ability (an identity threatening domain for women). Specifically, when the test was described as diagnostic of problem-solving ability, women performed worse when a performance-avoidance goal was induced than when no achievement goal was induced. This result was consistent with past research showing the negative effects of performance-avoidance goal adoption (for a review see Elliot, 2005). However, when the same task was described as diagnostic of math ability, an opposite pattern was observed: consistent with a regulatory fit perspective (Grimm et al., 2009), women tended to perform better when a performance-avoidance goal context was induced than when no 
goal was induced. This is consistent with the idea that inducing a performance-avoidance goal context "matches" the prevention concern induced by ST, thereby creating regulatory fit, which enhanced performance.

Finally, inducing a performance-approach goal did not enhance performance compared to inducing no achievement goal, in either math or problem-solving ability conditions. Results observed in ST conditions are consistent with the idea of regulatory fit.

Results of this study are counter-intuitive, particularly with regard to the achievement goals literature, because performance-avoidance goals are usually associated with negative outcomes (e.g., Elliot, 2005). It could be argued, however, that the differential effects of achievement goals on performance in the math versus problemsolving conditions are due not to the stereotype threatening nature of the math task, but to the way in which we manipulated ST, i.e., by describing the task as measuring math versus problem-solving ability. It is possible that when individuals believe they are performing a problem-solving task, they bring into play different cognitive processes than when they believe they are performing a math task, and these processes may have nothing to do with a threatening group stereotype.

In order to clarify the interpretation of these results and ascertain the reliability of the effects observed, we conducted a second study modelled closely on the first, except that the task was described as diagnostic of math ability in both the threatening and nonthreatening conditions. In addition, instead of activating stereotypes in a subtle manner by merely describing the task as diagnostic of math, Study 2 used an explicit stereotype activation, by comparing a condition in which participants are reminded of the gender 
differences existing in math performance to a condition in which the test is described as gender neutral.

A second goal of Study 2 was to investigate potential mediators of the hypothesized performance boost caused by inducing regulatory fit among women under ST. Experiencing regulatory fit has been shown to increase the value of what people are doing. This "value from fit" is associated with stronger engagement and more positive feelings (e.g., Higgins, 2000; 2005). The ability to think flexibly also improves when regulatory fit is higher, leading in turn to better performance (e.g., Grimm et al., 2009). This suggests that another process could be involved in regulatory fit: challenge appraisals. According to Lazarus and Folkman (1984), people experience challenge when they appraise their resources as sufficient to meet the demands of a task, and threat when they appraise the demands of a task as outweighing their resources for coping with it. Given that regulatory fit increases engagement, positive feelings and flexibility, we propose that regulatory fit could enhance people's appraisals of their resources, leading to higher challenge (relative to threat) appraisals. In turn, these appraisals could improve performance (e.g., Blascovich, Seery, Mugridge, Norris, \& Weisbuch, 2004; Chalabaev, Major, Cury, \& Sarrazin, 2009). Based on Folkman and Lazarus (1985), challenge and threat appraisals were indexed by emotions that have been identified as products of these appraisals. Specifically, challenge appraisal was measured by eagerness and confidence whereas threat appraisal was assessed by worry and nervousness (e.g., Elliot \& Harackiewicz, 1996; Folkman \& Lazarus, 1985).

Interestingly, regulatory focus theory has not considered eagerness and nervousness as outcomes of regulatory fit, but instead as outcomes of promotion and 
prevention concerns. The model indeed predicts that promotion-oriented individuals are inclined toward eagerness and prevention-oriented individuals toward vigilance (Higgins, 1997; 1998). Moreover, eagerness and vigilance are not conceptualized as emotions but rather as goal pursuit means. The current research thus differs from past regulatory focus studies by examining eagerness and nervousness as mechanisms of regulatory fit, and by considering these variables as emotions indicative of challenge and threat appraisals (e.g., Lazarus \& Folkman, 1985).

\section{Study 2}

\section{Method}

Participants. Fifty-eight female undergraduates at UCSB took part in this study for introductory psychology course credit or for $\$ 10$. As in Study 1, participants were randomly assigned to one of six conditions in a 2 (ST: Gender differences or No gender differences) $\times 3$ (Goal Type: Performance-avoidance or Performance-approach or No goal) between- subject factorial design.

Procedure and measures. The procedure was the same as in Study 1, with one major exception -- the nature of the ST manipulation. All participants listened to taperecorded instructions describing the task as a math task. Then, different instructions were given depending on condition assignment. Participants in the gender differences condition were told that the test had been shown to produce gender differences, whereas participants in the no gender differences group heard that the test had not been shown to produce gender differences. This ST manipulation was modelled on prior ST research (e.g., Spencer et al., 1999; Smith et al., 2007).

The achievement goal manipulation was identical to that used in Study 1. 
After hearing the instructions and as a check on the stereotype manipulation, participants rated the math performance of women and men on this test on a scale from 1 (very poor) to 7 (very good). The difference between these two items was computed and submitted to analyses, with higher scores indicating that participants perceived gender differences in favor of men. The items assessing the achievement goal manipulation were identical to those used in Study 1.

Participants next completed a questionnaire assessing challenge and threat appraisals with the anticipatory affect index used by Elliot and Harackiewicz (1996) and adapted from Folkman and Lazarus (1985). This scale included the stem "As I anticipate doing the test I feel...," and the following items: eager, confident, nervous, worried. Participants answered on a 7-point Likert scale from 1 (strongly disagree) to 7 (strongly agree). As in previous research (e.g., Elliot \& Harackiewicz, 1996), the first two items comprised the challenge appraisal $(\alpha=.93)$ and the last two items comprised the threat appraisal $(\alpha=.85)$. We analyzed these two appraisals separately and relatively to each other by calculating the difference between challenge and threat appraisals for each participant.

Finally, participants performed the same performance task as in Study 1, were then thanked and fully debriefed.

\section{Results and Discussion}

Manipulation checks. The manipulation checks were successful. A $2 \times 3$ ANOVA on the ST manipulation check revealed only a significant main effect of ST, $F(1,53)=21.17, p<.001, \eta^{2}=.29$, such that participants in the Gender differences condition thought men performed significantly better on the test $(M=1.51)$ more than did 
participants in the No gender differences condition $(M=0.27)$. A similar analysis performed on the "weak students" item revealed only a significant main effect of Goal Type, $F(2,53)=58.48, p<.001, \eta^{2}=.69$. Women in the Performance-avoidance goal conditions considered more that the purpose of the task was to identify the weak students $(M=5.72)$ than did women in the Performance-approach goal $(M=1.64), F(1,53)=$ 98.43, $p<.001, \eta^{2}=.65$, and No goal $(M=2.20)$ conditions, $F(1,53)=77.10, p<.001$, $\eta^{2}=.59$. The latter two conditions did not differ from each other, $F(1,53)=1.92, p=$ $.17, \eta^{2}=.04$. On the "strong students" item, the main effect of Goal Type was again significant, $F(2,53)=51.93, p<.001, \eta^{2}=.66$, with women in the Performanceapproach goal conditions considering more that the purpose of the task was to identify the strong students $(M=5.84)$ than women in the Performance-avoidance goal $(M=1.89)$, $F(1,53)=83.71, p<.001, \eta^{2}=.61$, and No goal $(M=2.25)$ conditions, $F(1,53)=72.99$, $p<.001, \eta^{2}=.58$. The latter two conditions did not differ significantly from one another $(F<1.00)$.

We also observed a significant main effect of ST on this item, $F(1,53)=4.51, p=$ .04 , such that participants perceived the task as designed to select the strong students more in the No gender differences condition $(M=3.70)$ than in the Gender differences condition $(M=2.96)$. No other significant effects appeared.

Task performance. As in Study 1, we conducted a 2 (ST) $\times 3$ (Goal Type) ANCOVA on performance accuracy controlling for SAT quantitative scores to test our predictions. The means and standard deviations of each experimental group are shown in Table 1. Only the predicted ST $\times$ Goal Type interaction was significant, $F(2,52)=4.82$, 
$p=.01, \eta^{2}=.16$ (see Figure 2). We probed the interaction using the same analytic approach used in Study 1.

First, we tested the simple main effect of ST in the No goal conditions. As predicted, and consistent with a classic ST effect, women in the No goal conditions performed more poorly on the math test when it was described as showing gender differences (Adj $M=0.57)$ than when it was described as showing no gender differences $(\operatorname{Adj} M=0.72), F(1,52)=4.09, p=.05, \eta^{2}=.07$.

Second, we examined the effect of performance-avoidance goal (vs. no goal) on task performance. Replicating the pattern shown in Study 1 as well as prior research showing the detrimental effects of adopting a performance-avoidance goal, women in the No threat condition performed marginally worse when a performance-avoidance goal context was induced ( $\operatorname{Adj} M=0.58), F(1,52)=3.27, p=.08, \eta^{2}=.06$. In contrast, replicating Study 1, when ST was induced, women performed significantly better in the Performance-avoidance goal condition (Adj $M=0.74), F(1,52)=5.58, p=.02, \eta^{2}=.10$. The performance of women in this condition did not differ from performance in the No goal/No threat condition $(F<1.00)$.

Third, we tested the effect of inducing a performance-approach goal context on task performance. Among women in the No threat condition, inducing a performanceapproach goal did not lead to better performance (Adj $M=0.66$ ) than inducing either a performance-avoidance goal or no goal $(F \mathrm{~S}<1.00)$. Among women in the ST conditions, however, inducing a performance-approach goal led to significantly better performance (Adj $M=0.74$ ) than inducing no goal, $F(1,52)=5.49, p=.02, \eta^{2}=.10$. The 
performance of women in the ST/performance-approach goal condition did not differ from performance in the No threat/No goal condition $(F<1.00)$.

\section{Do challenge appraisals mediate the moderating effects of performance goals}

on performance? We next tested our hypothesis that the moderation of ST effects by performance-avoidance goals was mediated by increased challenge appraisal (relative to threat $)^{3}$ associated with regulatory fit. We also explored the mediation of the moderation of ST by performance-approach goals. To do so we used the mediated moderation procedure recommended by Muller, Judd, and Yzerbyt (2005). According to these authors, three conditions must be met to demonstrate mediated moderation (for more details see Muller et al., 2005):

(1) The ST $\times$ Goal Type interaction effect on performance must be significant.

(2) The effect of ST on performance should be mediated by challenge appraisal (relative to threat), and one or both of the indirect paths from ST to performance must be moderated. That is, either the ST $\times$ Goal Type interaction effect on challenge is significant, and/or the partial challenge $\times$ Goal Type interaction effect on performance is significant.

(3) Finally, the residual ST $\times$ Goal Type effect on performance must be reduced compared to the total ST $\times$ Goal Type effect on performance.

In this study, the mediation of ST $\times$ Goal Type interaction by challenge appraisal (relative to threat) was tested separately for performance-avoidance and performanceapproach goals contexts. We assigned codes of 1 to females in the performanceavoidance (or approach) goal contexts, and codes of -1 to females in the no goal contexts. SAT scores were included in all analyses. Means and standard deviations of challenge 
appraisal, threat appraisal, and challenge relative to threat in each experimental group are described in Table 1.

Mediation of ST $\times$ performance-avoidance goal . Regression analyses showed that the ST $\times$ Performance-avoidance goal interaction significantly predicted performance, $\beta=-.40, t(35)=-2.67, p=.01, R^{2}=.16$, and challenge appraisal, $\beta=-.30$, $t(35)=-2.03, p=.05, R^{2}=.09$. Simple slopes analyses of this latter interaction effect revealed that challenge appraisal varied as a function of ST in the Performance-avoidance goal context but not in the no goal context (see Figure 3). More particularly, when both performance-avoidance goal and ST were induced, females tended to appraise the task more as a positive challenge than as a threat compared to when only performanceavoidance goal was induced, $\beta=-.39, t(35)=-1.80, p=.08, R^{2}=.07$. When no goal was induced, ST did not affect challenge appraisal, $\beta=.22, t(35)=1.06, p=.30, R^{2}=.03$.

The next regression analysis showed that the partial effect of challenge appraisal on performance (controlling for ST, Performance-avoidance goal, ST $\times$ Performanceavoidance Goal interaction and Performance-Avoidance Goal × challenge interaction) approached significance, $\beta=.28, t(33)=1.69, p=.10, R^{2}=.06$. In other words, the more females appraised the task as a positive challenge (relative to threat), the more they tended to perform well. We may conclude from these analyses that condition 2 of the mediated moderation procedure was partially satisfied. Finally, this third regression analysis indicated that compared to the moderation of the total effect of ST on performance, the moderation of the residual direct effect of ST on performance was reduced, $\beta=-.29, t(33)=-1.91, p=.06, R^{2}=.08$. Overall, these analyses suggest that 
challenge appraisal marginally mediated the moderation of ST effect on performance by Performance-avoidance goal.

Mediation of ST $\times$ performance-approach goal. Regression analyses showed that ST $\times$ Performance-approach goal interaction significantly predicted performance, $\beta=$ $-.36, t(35)=-2.29, p=.01, R^{2}=.13$. However, neither this interaction, $\beta=-.20, t(35)=-$ $1.23, p=.23, R^{2}=.04$, nor ST, $\beta=-.02, t(35)=0.11, p=.62, R^{2}=.00$, were significant predictors of challenge appraisal. Therefore, challenge did not mediate the moderation of ST effect on performance by Performance-approach goal.

\section{Summary}

Study 2 replicated the finding of Study 1 that the effects of inducing a performance-avoidance goal on performance differ depending on whether or not the situation produces ST. As predicted, for women not experiencing ST (the test was described as showing no gender differences), inducing a performance-avoidance goal led them to perform worse on the math test than inducing no achievement goal. In contrast, for women experiencing ST (the test was described as showing gender differences), inducing a performance-avoidance goal led to enhanced performance on the math test compared to inducing no goal. Furthermore, as predicted, the performance-avoidance goal induction also led women under ST to feel more challenged than threatened, and this appraisal marginally mediated the ST x performance-avoidance goal interaction on performance.

Study 2 also replicated Study 1 in that inducing a performance-approach goal did not lead to improved math performance among women in the no threat conditions compared to inducing no goal. Contrary to expectations, and in contrast to findings of 
Study 1, however, when the task was explicitly described as showing gender differences, inducing a performance-approach goal enhanced performance relative to inducing no goal. It did not, however, increase challenge appraisals. Thus, Study 2 showed that inducing either type of performance goal reduced ST effects on performance.

\section{General Discussion}

In two experiments, the present research found that inducing women experiencing stereotype threat to adopt a performance-avoidance goal (avoid performing poorly relative to others) reduced the negative effects of ST on math performance. Replicating past research on stereotype threat, we found that when no specific goal was induced, women performed more poorly on a math test when the situation activated concerns about confirming negative gender stereotypes, compared to when it did not. Likewise, replicating past research on achievement goals (e.g., Elliot, 2005), women not under ST performed more poorly on a math test when a performance-avoidance goal was induced compared to no-goal induction. In contrast, when both the negative stereotype that females are poor at math was made salient and a performance-avoidance goal was induced, women performed better on a math test. We observed this in two separate experiments using different manipulations of stereotype threat.

These counterintuitive results are consistent with regulatory fit theory (Higgins, 2000). According to this model, when people use a strategy compatible with their regulatory concerns, they experience regulatory fit and motivation, positive affect and performance increase (e.g., Camacho et al., 2003; Higgins, 2000; Lockwood et al., 2002). We believe that the state of mind of women under ST "fit" with the induced avoidance strategy, thereby leading to more positive affect (challenge appraisals) and better 
performance. Prior research has shown that individuals under ST adopt a goal of avoiding failure (e.g., Brodish \& Devine, 2009; Chalabaev et al., 2008; Seibt \& Förster, 2004). Because they are likely to be sensitive to the absence and presence of negative outcomes, being careful to avoid mistakes should be their preferred strategy for selfregulation (e.g., Grimm et al., 2009). This is precisely the strategy that inducing a performance-avoidance goal context encourages (i.e., avoid a poor performance relative to others). This interpretation of our results is reinforced by the finding that inducing a performance-avoidance goal context in women under ST enhanced challenge (relative to threat) appraisals, which were in turn associated with better performance. This suggests that regulatory fit enhances individuals' belief that they have sufficient resources to meet demands of the task, corroborating the value from fit hypothesis (Higgins, 2000; 2005) which predicts that when fit occurs, people engage more strongly in what they are doing and "feel right" about it.

In contrast to the consistent results observed with regard to performanceavoidance goals, the influence of inducing a performance-approach goal was less clear. Past research typically has shown a beneficial effect of inducing performance-approach goals on performance (e.g., Elliot, 2005). In both of the current experiments, however, inducing a performance-approach goal in the absence of ST did not improve performance relative to when no goal was induced. We think there are several reasons why this might have occurred. Although performance-avoidance goals have been consistently shown to have maladaptive outcomes, performance-approach goals have not always been associated with positive outcomes (e.g., Elliot, 2005). First, past studies have shown that effects of performance-approach goals are moderated by task difficulty (e.g., Barron \& 
Harackiewicz, 2001; Grant \& Dweck, 2003). For example, Barron \& Harackiewicz (2001, Study 1) found that performance-approach goals positively affected performance when a math task was easy but not when it was difficult. We used difficult math problems in our research, which may explain why inducing performance-approach goals did not enhance performance when stereotypes were not made salient. A second reason may be the gender of our participants. The benefits of adopting performance-approach goals appear to be stronger for males than for females (e.g., Bouffard, Boisvert, Vezeau, \& Larouche, 1995; Linnenbrink, Ryan, \& Pintrich, 1999), perhaps because females may be less comfortable with an emphasis on competition (e.g., Darnon, Dompnier, Delmas, Pulfrey, \& Butera, 2009; Linnenbrink et al., 1999). For example, Linnenbrink et al. (1999) reported that adopting performance-approach goals positively affected working memory functioning among males but not females. The fact that only females participated in our studies could explain why inducing a performance-approach goal did not improve performance in the no threat conditions. Third, unlike the current experiments, most prior experiments have compared the effects of inducing a performance-approach goal to the effects of inducing a performance-avoidance goal (e.g., Cury et al., 2002; Darnon, Harackiewicz, Butera, Mugny, \& Quiamzade, 2007; Elliot \& Harackiewicz, 1996; Elliot et al., 2005; Senko \& Harackiewicz, 2005). Very few have employed a control group in which no goal is induced. It is possible that the difference in performance observed between performance-avoidance and performance-approach goal conditions in prior research may be due more to the detrimental effect of a performanceavoidance goal (under nonthreatening conditions) than to the positive effect of a performance-approach goal. 
The effects of inducing a performance-approach goal in women under ST were inconsistent across the two studies. Consistent with a regulatory fit perspective, inducing a performance-approach goal in women under ST (relative to no-threat) was associated with worse performance in Study 1 . However, contrary to a regulatory fit perspective, in Study 2, inducing a performance-approach goal did improve the performance of women under ST (versus no threat), although it did not increase challenge appraisals. One potential explanation for this is that although performance-approach goals and promotion concerns share similarities (i.e., they are both approach-oriented), the particularity of performance-approach goals is that they focus on interindividual social comparisons. This specificity could explain why these goals do not necessarily lead to regulatory misfit under ST. Indeed, making participants focus on interindividual comparisons may have enhanced the salience of their personal identity, thus reducing activation of their gender identity. In turn, this may have alleviated ST effects. Interestingly, this effect occurred when ST was induced by reminding participants of gender differences in math performance (Study 2) but not when the task was described as diagnostic of math ability (Study 1). This suggests that performance-approach goals have positive effects only in a context that emphasizes social comparisons. Future research should examine this hypothesis in order to determine why and when performance-approach goals may reduce ST.

Does this interpretation question our regulatory fit hypothesis? We do not believe so, for at least two reasons. First, whereas performance-avoidance goals reduced ST effects consistently across studies, performance-approach goals alleviated ST in Study 2 only. This suggests that avoidance-oriented performance goals are more likely to reduce ST than approach-oriented performance goals, corroborating a regulatory fit hypothesis. 
Second, although both performance goals reduced ST in Study 2, challenge appraisals increased only when ST was coupled with performance-avoidance goals. It seems that performance goals effects under ST are driven by different processes depending on their valence (avoidance or approach), and again, that regulatory fit may account for the performance boost observed when ST was coupled with performance-avoidance goals.

This research has important theoretical implications for ST, achievement goal, and regulatory focus theories more generally. First, most of the research on ST has focused on identifying the types of groups and domains in which the theory applies; far fewer studies have examined psychological tools that may help negatively stereotyped individuals cope with ST (e.g., Alter et al., 2010; Forbes \& Schmader, 2010; Marx et al., 2005). The current research adds to this knowledge by identifying a novel and counterintuitive strategy that may help negatively stereotyped individuals cope with ST: adopting a performance-avoidance goal.

Second, this research challenges the idea that performance-avoidance goals are always bad for achievement. Past studies in achievement goal literature have consistently shown that endorsing or activating performance-avoidance goals has detrimental effects on achievement-related variables, such as motivation, anxiety, task absorption and performance (e.g., Elliot, 2005). In contrast, the present research shows that inducing a performance-avoidance goal may have positive effects when induced in a ST situation. This study does not question the fact that performance-avoidance goals have usually maladaptive outcomes. Instead, we argue that in specific conditions, inducing these goals may be beneficial. Identifying the contexts in which they may have positive effects could be an interesting line of research for the achievement goals theory. Given the counterintuitive nature of our results, they need to be replicated in future research. One 
could argue, for example, that placing individuals in a performance-avoidance goal context does not inevitably lead them to adopt performance-avoidance goals. Thus it is important to examine whether experimentally inducing this context leads individuals to adopt performance-avoidance goals.

Third, this research adds to a growing body of research demonstrating the potentially beneficial effects of regulatory fit for achievement-related behaviors (e.g. Freitas \& Higgins, 2002; Keller \& Bless, 2006; Lockwood, et al., 2002). Our experiments confirm the reliability of "stereotype fit" effects observed by Grimm et al. (2009) and extend them by showing that this phenomenon may occur not only when a prevention context is induced, but also when performance-avoidance goals are manipulated. Along with these authors, we believe it would be fruitful in future research to deepen our understanding of the possible mechanisms underlying this important achievement phenomenon. 


\section{References}

Alter, A. L., Aronson, J., Darley, J. M., Rodriguez, C., \& Ruble, D. N. (2010). Rising to the threat: Reducing stereotype threat by reframing the threat as a challenge. Journal of Experimental Social Psychology, 46, 166-171.

Aronson, J., Fried, C. B., \& Good, C. (2002). Reducing the effects of stereotype threat on African American college students by shaping theories of intelligence. Journal of Experimental Social Psychology, 38, 113-125.

Barron, K. E., \& Harackiewicz, J. M. (2002). Achievement goals and optimal motivation: Testing multiple goal models. Journal of Personality and Social Psychology, 80, 706-722.

Blascovich, J., Seery, M. D., Mugridge, C. A., Norris, R. K., \& Weisbuch, M. (2004). Predicting athletic performance from cardiovascular indexes of challenge and threat. Journal of Personality and Social Psychology, 40, 683-688.

Bouffard, T., Boisvert, J., Vezeau, C., \& Larouche, C. (1995). The impact of goal orientation on self-regulation and performance among college students. British Journal of Educational Psychology, 65, 317-329.

Brodish, A. B., \& Devine, P. G. (2009). The role of performance-avoidance goals and worry in mediating the relationship between stereotype threat and performance. Journal of Experimental Social Psychology, 45, 180-185.

Brown, R. P., \& Josephs, R. A. (1999). A burden of proof: Stereotype relevance and gender differences in math performance. Journal of Personality and Social Psychology, 76, 246-257. 
Camacho, C. J., Higgins, E. T., \& Luger, L. (2003). Moral value transfer from regulatory fit: What feels right is right and what feels wrong is wrong. Journal of Personality and Social Psychology, 84, 498-510.

Chalabaev, A., Major, B., Cury, F., \& Sarrazin, P. (2009). Physiological markers of challenge and threat mediate the effects of performance-based goals on performance. Journal of Experimental Social Psychology, 45, 991-994.

Chalabaev, A., Sarrazin, P., Stone, J., \& Cury, F. (2008). Do achievement goals mediate stereotype threat? An investigation on females' soccer performance. Journal of Sport \& Exercise Psychology, 30, 143-158.

Crowe, E., \& Higgins, E. T. (1997). Regulatory focus and strategic inclinations: Promotion and prevention in decision-making. Organizational Behavior and Human Decision Processes, 69, 117-132.

Cury, F., Elliot, A., Da Fonseca, D., \& Moller, A. (2006). The social cognitive model of achievement motivation and the $2 \times 2$ achievement goal framework. Journal of Personality and Social Psychology, 90, 666-679.

Cury, F., Elliot, A., Sarrazin, P., Da Fonseca, D., \& Rufo, M. (2002). The trichotomous achievement goal model and intrinsic motivation: A sequential mediational analysis. Journal of Experimental Social Psychology, 38, 473-481.

Darnon, C., Harackiewicz, J. M., Butera, F., Mugny, G., \& Quiamzade, A. (2007). Performance-approach and performance-avoidance goals: When uncertainty makes a difference. Personality and Social Psychology Bulletin, 33, 813-827. 
Darnon, C., Dompnier, B., Delmas, F., Pulfrey, C., \& Butera, F. (2009). Achievement goal promotion at university: Social desirability and social utility of mastery and performance goals. Journal of Personality and Social Psychology, 96, 119-134.

Elliot, A. J. (2005). A conceptual history of the achievement goal construct. In A. Elliot \& C. Dweck (Eds.), Handbook of competence and motivation (pp. 52-72). New York: Guilford Press.

Elliot, A. J., \& Church, M. A. (1997). A hierarchical model of approach and avoidance achievement motivation. Journal of Personality and Social Psychology, 72, 218232.

Elliot, A. J., \& Harackiewicz, J. M. (1996). Approach and avoidance achievement goals and intrinsic motivation: A mediational analysis. Journal of Personality and Social Psychology, 70, 461-475.

Elliot, A. J., \& McGregor, H. A. (1999). Test anxiety and the hierarchical model of approach and avoidance achievement motivation. Journal of Personality and Social Psychology, 76, 628-644.

Elliot, A. J., McGregor, H. A., \& Gable, S. (1999). Achievement goals, study strategies, and exam performance: A mediational analysis. Journal of Educational Psychology, 91, 549-563.

Elliot, A. J., Shell, M. M., Bouas, H. K., \& Maier, M. A. (2005). Achievement goals, performance contingencies, and performance attainment: An experimental test. Journal of Educational Psychology, 97, 630-640.

Folkman, S., \& Lazarus, R. S. (1985). If it changes it must be a process: Study of emotion and coping during three stages of a college examination. Journal of Personality 
and Social Psychology, 48, 150-170.

Forbes, C. E., \& Schmader, T. (2010). Retraining attitudes and stereotypes to affect motivation and cognitive capacity under stereotype threat. Journal of Personality and Social Psychology, 99, 740-754.

Freitas, A. L., \& Higgins, E.T. (2002). Enjoying goal-directed action: The role of regulatory fit. Psychological Science, 13, 1-6.

Friedman, R. S., \& Förster, J. (2001). The effects of promotion and prevention cues on creativity. Journal of Personality and Social Psychology, 81, 1001-1013.

Goff, P. A., Steele, C. M., \& Davies, P. G. (2008). The space between us. Journal of Personality and Social Psychology, 94, 91-107.

Grant, H., \& Dweck, C. S. (2003). Clarifying achievement goals and their impact. Journal of Personality and Social Psychology, 85, 541-553.

Grimm, L. R., Markman, A. B., Maddox, W. T., \& Baldwin, G. C. (2009). Stereotype threat reinterpreted as a regulatory mismatch. Journal of Personality and Social Psychology, 96, 288-304.

Harackiewicz, J. M., Barron, K. E., Pintrich, P. R., Elliot, A. J., \& Thrash, T. M. (2002). Revision of achievement goal theory: Necessary and illuminating. Journal of Educational Psychology, 94, 638-645.

Higgins, E. T. (1997). Beyond pleasure and pain. American Psychologist, 52, 1280-1300.

Higgins, E. T. (1998). Promotion and prevention: Regulatory focus as a motivational principle. Advances in Experimental Social Psychology, 46, 1- 46.

Higgins, E. T. (2000). Making a good decision: Value from fit. American Psychologist, $55,1217-1230$. 
Higgins, E. T. (2005). Value from regulatory fit. Current Directions in Psychological Science, 14, 209-213.

Inzlicht, M., \& Ben Zeev, T. (2000). A threatening intellectual environment: Why females are susceptible to experiencing problem-solving deficits in the presence of males. Psychological Science, 11, 365-371.

Johns, M., Schmader, T., \& Martens, A. (2005). Knowing is half the battle. Teaching stereotype threat as a means of improving women's math performance. Psychological Science, 16, 175-179.

Keller, J., \& Bless, H. (2006). Regulatory fit and cognitive performance: The interactive effect of chronic and situational self-regulatory mechanisms on cognitive test performance. European Journal of Social Psychology, 36, 393-405.

Lawrence, J. S., Marks, B. T., \& Jackson, J. S. (2010). Domain identification predicts black students' underperformance on moderately-difficult tests. Motivation and Emotion, 34, 105-109.

Lazarus, R. S., \& Folkman, S. (1984). Coping and adaptation. In W. D. Gentry (Ed.), The handbook of behavioral medicine (pp. 282-325). New York: Guilford.

Linnenbrink, E., Ryan, A., \& Pintrich, P. R. (1999). The role of goals and affect in working memory functioning. Learning and Individual Differences, 11, 213-230.

Lockwood, P., Jordan, C. H., \& Kunda, Z. (2002). Motivation by positive or negative role models: Regulatory focus determines who will best inspire us. Journal of Personality and Social Psychology, 83, 854-864. 
Martens, A., Johns, M., Greenberg, J., \& Schimel, J. (2006). Combating stereotype threat: The effect of self-affirmation on women's intellectual performance. Journal of Experimental Social Psychology, 42, 236-243.

Marx, D. M., Ko, S. J., \& Friedman, R. A. (2009). The "Obama Effect": How a salient role model reduces race-based performance differences. Journal of Experimental Social Psychology, 45, 953-956.

Marx, D. M., Stapel, D. A., \& Muller, D. (2005). We can do it: The interplay of construal orientation and social comparisons under threat. Journal of Personality and Social Psychology, 88, 432-446.

McIntyre, R. B., Paulson, R. M., \& Lord, C. G. (2002). Alleviating women's mathematics stereotype threat through salience of group achievements. Journal of Experimental Social Psychology, 39, 83-90.

Muller, D., Judd, C., \& Yzerbyt, V. (2005). When moderation is mediated and mediation is moderated. Journal of Personality and Social Psychology, 89, 852-863.

Murayama, K., \& Elliot, A. J. (2009). The joint influence of personal achievement goals and classroom goal structures on achievement-relevant outcomes. Journal of Educational Psychology, 101, 432-447.

Schmader, T. (2002). Gender identification moderates stereotype threat effects on women's math performance. Journal of Experimental Social Psychology, 38, 194201.

Schmader, T., Johns, M., \& Forbes, C. (2008). An integrated process model of stereotype threat effects on performance. Psychological Review, 115, 336-356. 
Seibt, B., \& Förster, J. (2004). Stereotype threat and performance: How self-stereotypes influence processing by inducing regulatory foci. Journal of Personality and Social Psychology, 87, 38-56.

Senko, C. M., \& Harackiewicz, J. M. (2005). Achievement goals, performance and task interest: Why perceived difficulty matters. Personality and Social Psychology Bulletin, 31, 1739-1753.

Shah, J., Higgins, E. T., \& Friedman, R. S. (1998). Performance incentives and means: How regulatory focus influences goal attainment. Journal of Personality and Social Psychology, 74, 285-293.

Shih, M., Pittinsky, T. L., \& Ambady, N. (1999). Stereotype susceptibility: Identity salience and shifts in quantitative performance. Psychological Science, 10, 80-83.

Smith, J. L., Sansone, C., \& White, P. H. (2007). The stereotyped task engagement process: The role of interest and achievement motivation. Journal of Educational Psychology, 99, 99-114.

Spencer, S. J., Steele, C. M., \& Quinn, D. M. (1999). Stereotype threat and women's math performance. Journal of Experimental Social Psychology, 35, 4-28.

Steele, C. M. (1997). A threat in the air: How stereotypes shape intellectual identity and performance. American Psychologist, 52, 613-629.

Steele, C. M., \& Aronson, J. (1995). Stereotype threat and the intellectual test performance of African Americans. Journal of Personality and Social Psychology, 69, 797-811.

Urdan, T. C. (2004). Predictors of self-handicapping and achievement: Examining achievement goals, classroom structures, and culture. Journal of Educational 
Psychology, 96, 251-264.

Van Yperen, N. W. (2003). Task interest and actual performance: The moderating effects of assigned and adopted purpose goals. Journal of Personality and Social Psychology, 85, 1006-1015. 


\section{Footnotes}

${ }^{1}$ This research was supported by a Marie Curie fellowship from the European Commission. We wish to express our gratitude to Heidi Nyberg, Kathryn Chaimov, and Stacy Springmeyer for their help in collecting data.

${ }^{2}$ We examined these latter goals only, because they have been shown to be good predictors of performance, whereas mastery goals are associated with different outcomes such as intrinsic motivation and enjoyment (e.g., Cury, Elliot, Da Fonseca, \& Moller, 2006; Harackiewicz et al., 2002).

${ }^{3}$ Mediated moderation analyses were also conducted with challenge and threat appraisals separately and did not reveal significant effects. 
Table 1.

Mean (Standard Deviation) Performance Score, Challenge and Threat appraisals as a Function of Test Description and Goal Type in Study 1 and Study 2.

\begin{tabular}{|c|c|c|c|c|c|c|}
\hline \multirow[b]{2}{*}{ Variable } & \multicolumn{3}{|c|}{ Study 1} & \multicolumn{3}{|c|}{ Study 2} \\
\hline & Perf-Av. Goal & No Goal & Perf-App. Goal & Perf-Av. Goal & No Goal & Perf-App. Goal \\
\hline \multicolumn{7}{|l|}{ Task Performance } \\
\hline Stereotype Threat & $0.61(0.20)$ & $0.47(0.18)$ & $0.56(0.28)$ & $0.74(0.17)$ & $0.57(0.24)$ & $0.74(0.09)$ \\
\hline No threat & $0.55(0.21)$ & $0.69(0.21)$ & $0.66(0.25)$ & $0.58(0.18)$ & $0.72(0.11)$ & $0.66(0.15)$ \\
\hline
\end{tabular}

Challenge (relative

to threat)

$\begin{array}{rllllll}\text { Stereotype Threat } & - & - & - & 0.78(2.56) & -1.53(1.79) & 0.19(2.44) \\ \text { No threat } & - & - & - & -1.09(2.32) & -0.49(2.56) & -0.56(2.65)\end{array}$

Challenge appraisal

Stereotype Threat

$\begin{array}{lll}- & 4.29(1.11) & 3.02(1.27)\end{array} 3.83(1.66)$


No threat

Threat appraisal

Stereotype Threat

No threat

-
-
-

$-$

$3.61(1.42)$

$3.26(1.21)$

$3.83(1.58)$

$-$

$3.61(1.42)$

$-$

$3.51(1.72)$

- $\quad 4.70(1.28)$

$4.70(1.28)$

$4.55(1.06)$

$3.64(1.64)$

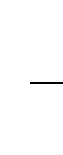

Note. Perf-Av. means Performance-Avoidance, Perf-App. means Performance-Approach. All means are adjusted for SAT score.

Stereotype Threat refers to Math ability condition in Study 1 and Gender Differences condition in Study 2. No threat refers to Problem-solving ability condition in Study 1 and No Gender Differences condition in Study 2. 


\section{Figure Captions}

Figure 1. Effects of test description and goal type on task performance (Study 1).

Figure 2. Effects of test description and goal type on task performance (Study 2).

Figure 3. The relationship between performance-based goal and challenge appraisal in the gender differences and no gender differences conditions. 
Figure 1.

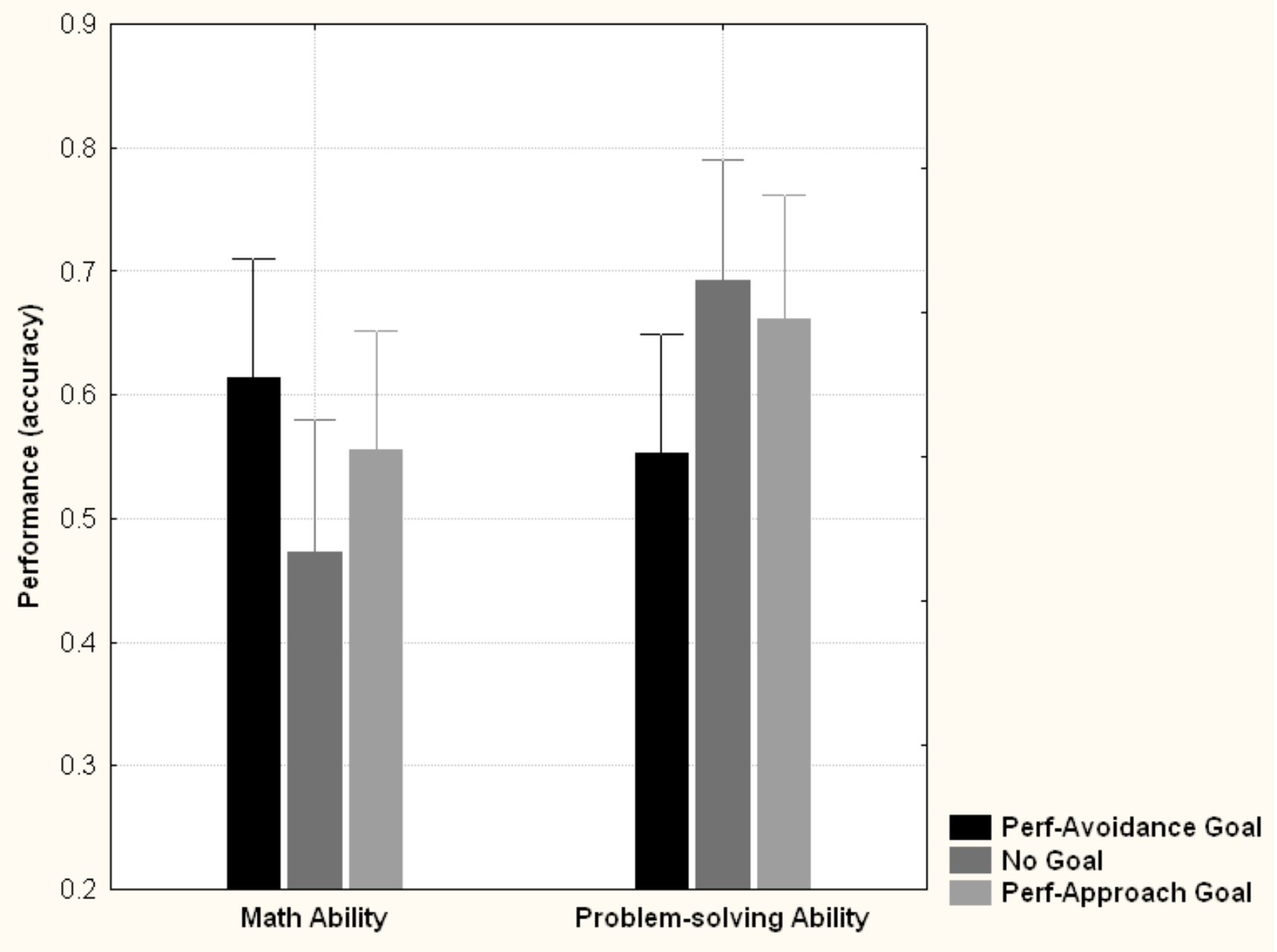

Note. Error bars indicate standard error. 
Figure 2.

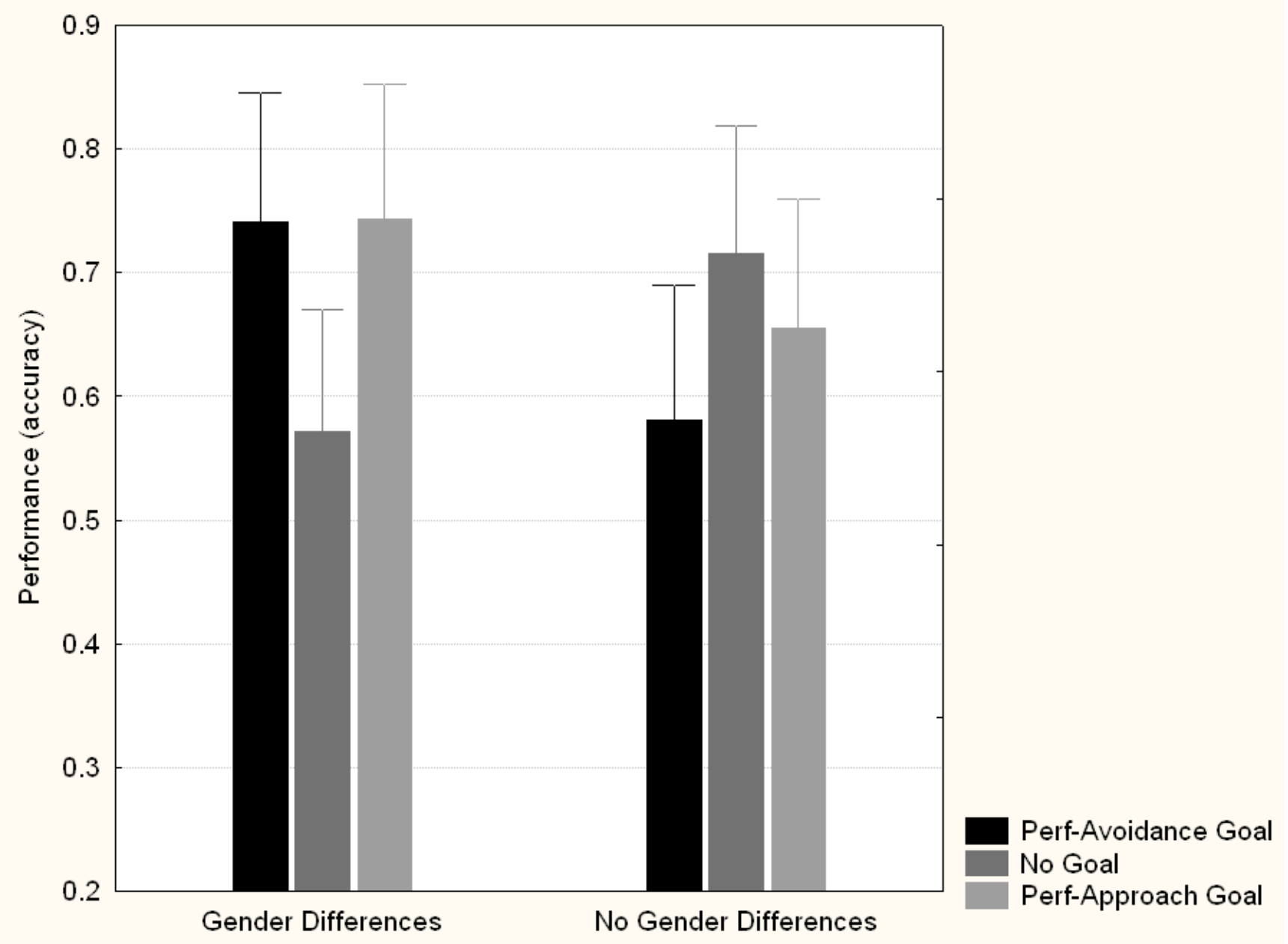

Note. Error bars indicate standard error. 
Figure 3.

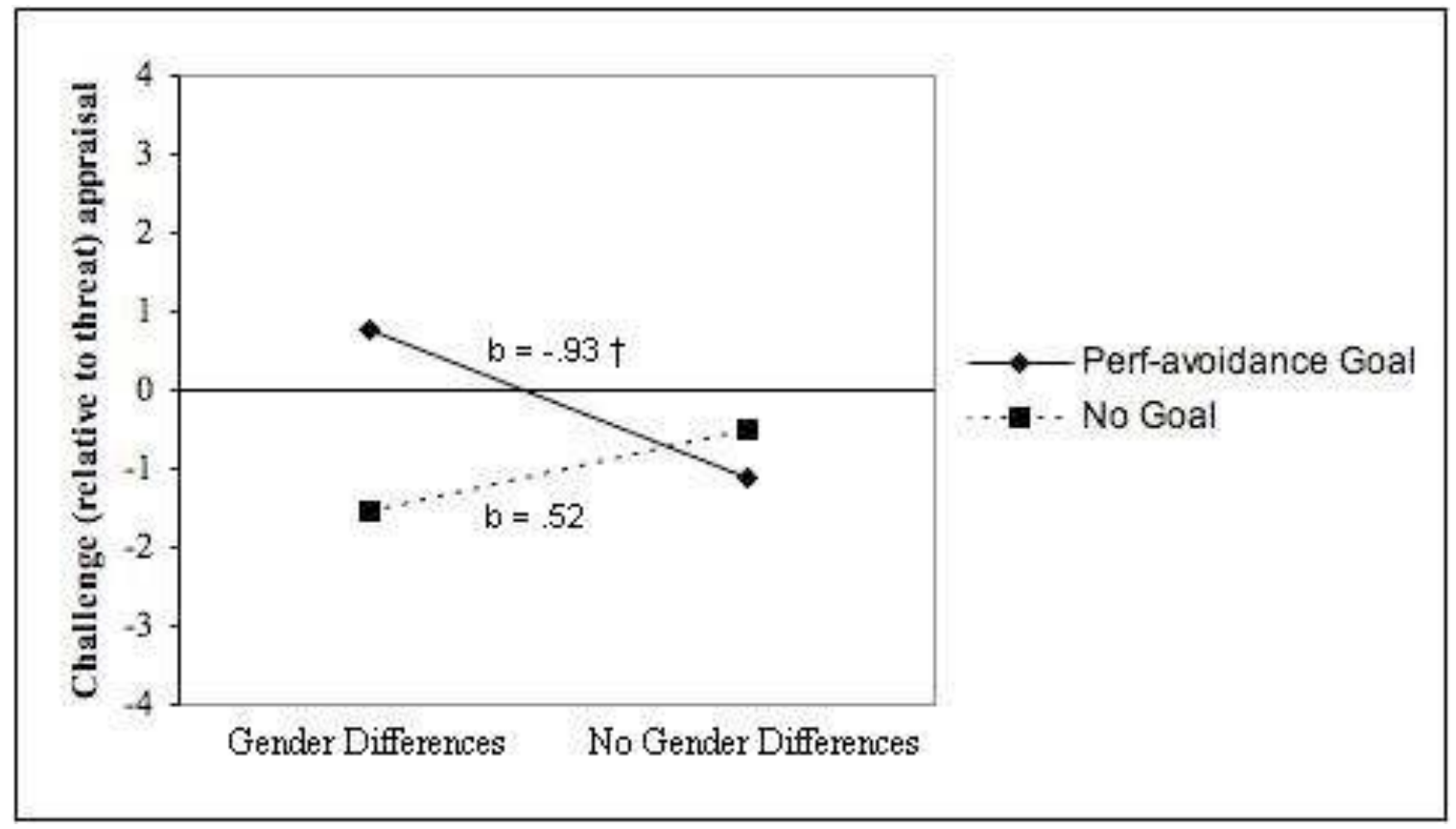

Note. ${ }^{\dagger} \mathrm{p}=.08$. 